\title{
Myxidium scripta n. sp. identified in urinary and biliary tract of Louisiana-farmed red-eared slider turtles Trachemys scripta elegans
}

\author{
John F. Roberts ${ }^{1,5, *}$, Christopher M. Whipps ${ }^{4,6}$, Jerri L. Bartholomew ${ }^{4}$, \\ Lynda Schneider ${ }^{2}$, Elliott R. Jacobson ${ }^{3}$
}

\begin{abstract}
${ }^{1}$ Department of Infectious Disease and Pathology, College of Veterinary Medicine; ${ }^{2}$ The Electron Microscopy Core Laboratory, Biotechnology Program; ${ }^{3}$ Department of Small Animal Clinical Sciences, College of Veterinary Medicine; University of Florida, Gainesville, Florida 32610, USA

${ }^{4}$ Center for Fish Disease Research, Department of Microbiology, Oregon State University, Corvallis, Oregon 97331, USA

${ }^{5}$ Present address: Thompson-Bishop-Sparks State Diagnostic Laboratory, PO Box 2209, Auburn, Alabama 36831, USA

${ }^{6}$ Present address: Environmental and Forest Biology, State University of New York College of Environmental Science and Forestry, Syracuse, New York 13210, USA
\end{abstract}

\begin{abstract}
During a necropsy investigation of a mortality event occurring at a turtle farm in Assumption Parish, Louisiana, spores of a myxozoan were identified in the renal tubules in 3 of 6 , the gall bladder lumen in 2 of 6 , and the bile ductule in 1 of 6 red eared slider turtles Trachemys scripta elegans. In total, myxozoa were identified in 4 of 6 turtles. In 1 turtle, renal tubules contained numerous mature spores, had epithelial hyperplasia, granulomatous transformation, compression of adjacent tubules and interstitial lymphocytic nephritis. The genus of myxozoan was Myxidium, based on spore morphology in cytological preparations, in histologic section, and by electron microscopy. In cytological preparation the spores had mean dimensions of $18.8 \times 5.1 \mu \mathrm{m}$ and a mean polar capsule dimension of $6.6 \times 3.5 \mu \mathrm{m}$. Electron microscopy showed renal tubules contained plasmodia with disporoblasts with spores in various stages of maturation. Ultrastructure of mature spores demonstrated a capsule containing 2 asymmetrical overlapping valves and polar capsules containing a polar filament coiled 6 to 8 times and surrounded by a membrane composed of a double layer wall. The small subunit rDNA gene sequence was distinct from all other Myxidium species for which sequences are available. Additionally, this is the first Myxidium species recovered from a North American chelonian to receive genetic analysis. Although T. s. elegans is listed as a host for Myxidium chelonarum, this newly described species of Myxidium possessed larger spores with tapered ends; thus, we described it as a new species, Myxidium scripta n. sp. This report documents a clinically significant nephropathy and genetic sequence from a Myxidium parasite affecting a freshwater turtle species in North America.
\end{abstract}

KEY WORDS: Myxidium · Trachemys scripta elegans $\cdot$ Red-eared slider turtle $\cdot$ Myxozoa $\cdot$ Kidney Nephritis · Ultrastructure $\cdot$ rDNA sequence

\section{INTRODUCTION}

The phylum Myxozoa contains at least 62 genera, including the genus Myxidium (order Bivalvulida, suborder Variisporina), that are coelozoic metazoan parasites infecting biliary, urinary and gastrointestinal tracts of aquatic vertebrates (Padros et al. 2001, Gar- ner et al. 2005, Helke \& Poynton 2005). Myxidium contains some 217 reported species described in saltwater fish, freshwater fish, a few amphibians, and several turtles (Kent et al. 2001, Jirků et al. 2006, Lom \& Dyková 2006). Some Myxidium-like species exhibit low host specificity and have variable pathogenicity as shown by the case of Enteromyxum leei (formerly 
Myxidium leei), which infected the gastrointestinal tract of 25 species of marine fish at a public aquarium (Padros et al. 2001). In amphibians, Myxidium species can have a broad host range, as illustrated by the presence of $M$. serotinum in gall bladder extract from 6 of 28 amphibian species surveyed in Arkansas and Texas (McAllister \& Trauth 1995). M. melleni was found in 2 of 6 species of amphibian surveyed in Nebraska (Jirků et al. 2006). Both a broad geographic and host distribution were reported for $M$. immersum, which has been recorded from 36 amphibian hosts in South America, Australia, and Europe (Eiras 2005). It is unknown whether this truly represents a widely distributed species or a species complex because genetic sequencing of representative samples has not been conducted.

All myxozoans known to infect reptiles are in the genus Myxidium and all reports involve aquatic turtles. Five species of Myxidium have been named (Eiras 2005, Helke \& Poynton 2005). M. mackiei was discovered in the urinary excretory system of turtles in India and France by Bosanquet (1910). Subsequently, parasite-host interaction and extensive ultrastructure was recently described for this species in IndoGangetic flap-shelled turtles wild-caught in India and Pakistan (Helke \& Poynton 2005). Kudo (1919) identified $M$. americanum from the renal tubules of the spiny softshell turtle Trionyx (Apalone) spiniferus spiniferus in Illinois. Despite the presence of spores in the urine, no infection was identified in the renal tubules or collecting ducts of these turtles. The morphology of $M$. chelonarum was described by Johnson (1969), who later identified the organism in gall bladder extracts and some urine samples from 14 of 21 freshwater turtle species studied in the South Eastern United States and Mexico. Included in his study are host records from a Trachemys hybrid from Lee County, Alabama, and another red-eared slider (RES) from an unknown location (Johnson 1969). Most recently, Garner et al. (2005) described renal lesions caused by $M$. hardella in 2 Crown River turtles Hardella thurjii imported into the United States from Pakistan. This was the first publication using ribosomal DNA analysis to support a Myxidium species description (Garner et al. 2005).

RES are medium-sized aquatic turtles (carapace length up to $28 \mathrm{~cm}$ in females and $21 \mathrm{~cm}$ in males) and one of the most abundant turtle species in their United States range, which encompasses the Mississippi Basin and western Gulf drainage. These turtles are carnivores while young but progress to become omnivores as adults (Ernst et al. 1994). RES are the most common species of turtle in the pet trade and are commonly exported outside the United States. To meet this demand, RES farming operations have been established in the lower Mississippi Valley.
Although RES are reported as a host for Myxidium chelonarum (Johnson 1969), we identified a morphologically distinct Myxidium species infecting this species. Here we describe the morphology and phylogenetic position of M. scripta n. sp. and lesions associated with infection in farmed RES.

\section{MATERIALS AND METHODS}

RES. RES farmed for the pet trade were contained in $0.4 \mathrm{hm}^{2}$ (1 acre) ponds at a density of approximately 25000 turtles per pond in Assumption Parish, Louisiana. The turtles examined in this report were originally euthanized to diagnose the cause of a pneumonia-associated mortality event in May 2004 that killed approximately $10 \%$ of the population. Moribund turtles were unable to dive, exhibited inappropriate basking behavior and had severe pneumonia at necropsy. Six severely affected adult turtles (5 female, 1 male) were anesthetized using an overdose of ketamine (VetaKet, Lloyd Laboratory) injected subcutaneous at $200 \mathrm{mg} \mathrm{kg}^{-1}$ (Holz \& Holz 1995). After achieving a deep plane of anesthesia, a scalpel was used for partial decapitation immediately behind the head resulting in cervical disarticulation and severance of the spinal cord. Euthanized turtles were airtransported on ice to the University of Florida's College of Veterinary Medicine Diagnostic Anatomic Pathology service for post-mortem evaluation beginning approximately $24 \mathrm{~h}$ post euthanasia.

Pathological evaluation and sample collection. Necropsy was initiated immediately upon arrival, with removal of the plastron by a cast cutting saw (Stryker Instruments). The skull was cracked at the nasal septum with pruning shears and then pulled apart exposing the brain intact. Brain and nasal structures were removed using careful dissection with a scalpel blade. Intact gastrointestinal lumen was injected with $10 \%$ neutral buffered formalin (NBF) and the remaining entire viscera were placed intact into 101 buckets of NBF. Sections of all major organ systems were collected and routinely processed for light microscopy. Embedded tissues were sectioned at $5 \mu \mathrm{m}$ and stained with hematoxylin and eosin (H\&E). Brown and Brenn (B\&B) Gram stains, Giemsa and Zeihl-Neelsen acidfast were used on sections containing lung, gall bladder, liver, pancreas, right and left kidneys. WarthinStarry, Grocott's Method for Fungi (GMS) and Fite's acid fast stains were additionally used on sections of kidney containing numerous granulomas (Luna 1968).

Examination of pond sediment. Four $\sim 500 \mathrm{ml}$ fresh mud samples from the pond where the turtles originated were shipped on ice to the Center for Fish Disease Research, Department of Microbiology, Oregon 
State University. Sediment was placed in a shallow white tray with water and examined for the presence of oligochaetes. The water in which the samples were shipped was filtered through a $20 \mu \mathrm{m}$ mesh screen and the retained material was washed into a small Petri dish and examined under phase contrast at 100x magnification for waterborne actinospores. The samples were pooled, added into approximately 11 of water and then constantly aerated while being held in an incubator at $14^{\circ} \mathrm{C}$. The inoculated water was filtered 2 additional times over the subsequent month. Ten oligochaetes were squashed and examined at $200 \times$ for the presence of myxozoan organisms.

Measurement of Myxidium spores. Impression smears of fresh frozen kidney from 3 turtles were made and examined using light microscopy. Sixty spores were examined and photographed and measured digitally (Spot RT Software 3.0, Diagnostic Instruments). Spore length, width, and polar capsule lengths and widths were measured following the guidelines of Lom \& Arthur (1989). When visible, numbers of polar filament coils were recorded. Additionally, 20 mature spores in renal histologic sections were photographed and measured with a calibrated digital scale.

Transmission electron microscopy (TEM). Portions of paraffin-embedded kidneys from 2 turtles corresponding to areas with renal intra-tubular myxozoan parasites were excised, deparaffinized, and submitted for TEM. The sample was post-fixed in $2 \%$ buffered osmium tetroxide. Following osmification, tissue was buffer washed, dehydrated through a graded acetone series and finally infiltrated and embedded in Embed 812 epoxy resin formulation (Spurr 1969). Thick sections $(300 \mathrm{~nm})$ were cut, mounted on glass slides, stained with toluidine blue and examined by light microscopy. Thin sections (80 nm) were mounted on 400 mesh copper grids, stained for 10 min with $2 \%$ uranyl acetate (aq) and 5 min with Reynold's lead citrate and examined at $75 \mathrm{kV}$ accelerating voltage in a Hitachi H-7000 transmission electron microscope (Reynolds 1963).

DNA amplification and sequencing. The DNeasy Tissue Kit (QIAGEN Sample \& Assay Technologies) was used to extract DNA from kidney tissue of 3 turtles infected with the myxozoan. Overlapping regions of the small subunit (SSU) rDNA were amplified with PCR primers as described by Jirků et al. (2006). Amplification products were sequenced in both directions with PCR primers using AP Biotech ${ }^{\circledR}$ DYEnamic ET Terminator cycle sequencing chemistry with Thermo Sequenase II (Amersham Biosciences) on an ABI PRISM ${ }^{\circledR} 377$ DNA Sequencer (Applied Biosystems). The resulting sequence fragments were manually aligned, yielding a 2071 nucleotide (nt) contiguous sequence of SSU rDNA.
Phylogenetic analysis. The SSU rDNA sequence of Myxidium scripta n. sp. was aligned to SSU sequences of other species in the suborder Variisporina and sequences from relevant basic logical alignment search tool (BLAST) matches on GenBank. Marine Enteromyxum species were used as outgroup taxa. Nucleic acid sequence alignments were conducted in ClustalX (Thompson et al. 1997) using default settings. The resultant sequence alignment was then edited by eye to remove ambiguous regions or suspected base calling errors where positions of homology were questionable, yielding a 1793 character alignment. Phylogenetic analyses using parsimony, distance, and maximum likelihood algorithms were conducted in PAUP*4.01 (Swofford 1998). Bayesian analysis (BA) was conducted using MrBayes v. 3.0 (Ronquist \& Huelsenbeck 2003). Parsimony analyses (MP) were conducted using a heuristic search algorithm with 10 random additions of sequences and tree bisectionreconnection (TBR) branch swapping. Bootstrap values were calculated with 100 replicates using a heuristic search algorithm with simple sequence addition and TBR branch swapping. An optimal evolutionary model $(\mathrm{GTR}+\mathrm{G}+\mathrm{I})$ for the alignment was determined using Modeltest 3.06 (Posada \& Crandall 1998). Maximum likelihood (ML) analysis employed a heuristic search algorithm with random sequence addition and TBR branch swapping. Bootstrap confidence values were calculated with 100 repetitions. Distance analyses were conducted using likelihood distances and neighbor-joining tree construction. Tree construction using BA was run with 4 simultaneous Monte Carlo chains for $10^{6}$ generations, sampling every 100 generations, with a burn-in of 100 trees.

\section{RESULTS}

\section{General pathological findings}

All turtles arrived in a very good state of postmortem preservation. The 5 females had an average weight of $988 \mathrm{~g}$ (range 704 to $1320 \mathrm{~g}$ ) and the male weighed $520 \mathrm{~g}$. In all turtles the eyes were recessed in their orbits and the plastron and carapace of 2 turtles had low numbers of pin-point excoriations. Gastrointestinal contents were minimal and metazoan parasites were observed in the esophagus/stomach and proximal small intestine of 3 turtles. The acanthocephalan Neoechinorhynchus emyditoides, usually found in the small intestine, was identified in the distal esophagus and stomach of 2 turtles. Nematodes Serpinema trispinosus (2 turtles) and Siroxys contorta (1 turtle) were identified in the small intestines. By microscopic examination, 1 turtle had numerous bacteria- 
associated granulomas throughout the liver and nematode-associated granulomas in the small intestine. This turtle also had the most severe infection of myxidium in the kidney. All turtles had evidence of bacteriaassociated pneumonia manifested in some as regional necrosis of lungs or coelomitis of the adjacent tissues. Four of the female turtles had active follicular activity with as many as 80 developing follicles. Clinically significant microscopic findings included 6 of 6 turtles with proliferative and interstitial pneumonia and 3 of 6 turtles with severe regionally extensive necrotizing pneumonia containing mixed bacterial growth. Other findings included 3 of 6 with pancreatic duct fibrosis and 6 of 6 with splenic inflammation. Cardiovascular spirorchiid (Spirorchis) fluke eggs and immature flukes were observed in the liver, spleen, pancreas, lungs and kidneys of 5 of 6 turtles. Occasional spirorchiid emboli in the same section were encased in a thin layer composed of 2 to 4 fibrocytes with minimal inflammatory response. No spirorchiid fragments were observed in the larger granulomas.

\section{Myxozoan-associated pathological findings}

Using H\&E staining, spores and plasmodia of a myxozoan were identified in the renal tubules in 3 of 6 , the gall bladder lumen in 2 of 6 and the bile ductules in 1 of 6 turtles. Polar capsule and sporoplasm staining was enhanced greatly by B\&B Gram stain and Giemsa stains. Low numbers of spores were present in renal tubules of 2 turtles. The tubular lumen of these turtles contained sporogonic plasmodia with clearly defined ectoplasm borders that were best visualized with $\mathrm{H} \& \mathrm{E}$ stain (Fig. 1a). Clearly defined plasmodia with mature spores were identified in the lumen of bile ductules in
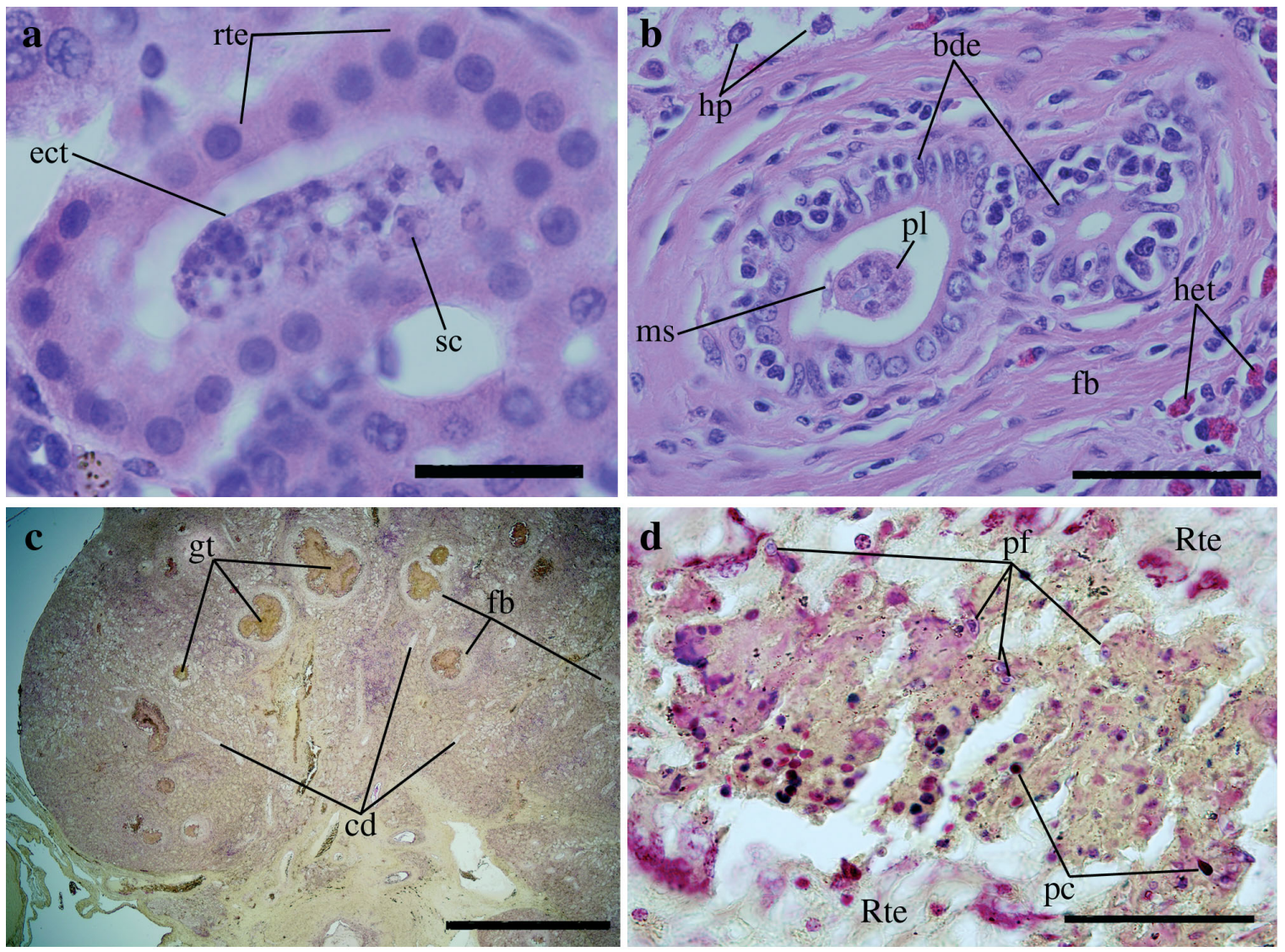

Fig. 1. Trachemys scripta elegans. (a) Kidney, H\&E, renal tubule demonstrating sporogonic plasmodium with clearly defined border of ectoplasm (ect) containing sporogonic cells (sc) closely adhered to renal tubular epithelial cells (rte). Scale bar $=25 \mu \mathrm{m}$. (b) Liver, H\&E, bile ductule lumen contains free myxospores (ms) and a plasmodium (pl) containing sporogonic cells. The bile ductules are duplicated with dysplastic epithelium (bde), surrounded by fibrosis (fb) and bordered by heterophils (het) and vacuolated hepatocytes (hp). Scale bar $=50 \mu \mathrm{m}$. (c) Kidney, B\&B Gram stain, transverse subgross cross-section showing granulomatous renal tubules (gt) surrounded by fibrosis (fb). Collecting duct tracts (cd) do not contain granulomas. Scale bar $=2 \mathrm{~mm}$. (d) Kidney, B\&B Gram stain, dilated renal tubule containing numerous spores and polar capsules (pc) with visible polar filaments (pf), surrounded by hyperplastic renal tubular epithelium (Rte). Scale bar $=50 \mu \mathrm{m}$ 
1 turtle (Fig. 1b). The most severely parasitized turtle had dilated renal tubules containing luminal cellular debris mixed with numerous sporogonic and presporogonic stages. There was proliferation of renal tubular epithelium, granulomatous differentiation of renal tubular epithelial cells, peritubular fibrosis and adjacent interstitial nephritis. One complete $5 \mu \mathrm{m}$ transverse section of right and left kidneys contained 22 and 30 granulomas, respectively, with granulomas ranging from 200 to $900 \mu \mathrm{m}$ in diameter. Granulomas were distributed primarily through the central region of the renal parenchyma in areas with architectural affinity for proximal and distal renal tubules between columns of collecting ducts (Fig. 1c). The centers of the granulomas contained cellular debris mixed with some clearly identifiable heterophils and sporogonic and mature spores (Fig. 1d). Other nuclei present in granulomas could not be classified with light microscopy but were believed to consist of mononuclear inflammatory cells and other presporogonic myxidium stages. The lumen with cellular debris was surrounded by layers of large polygonal dysplastic epithelial cells often with multiple nuclei. The epithelial layer was surrounded by up to 10 layers of fibrocytes and collagen. In areas where granulomas coalesced the interstitium contained aggregates of lymphocytes and macrophages. Other non granulomatous tubules had mildly dilated lumens containing up to 5 layers of spores in parallel arrangement and fewer sporogonic plasmodia. Spores were most consistent with a myxozoan of the genus Myxidium and are described below.

\section{Examination of pond sediment (mud)}

The 21 of sediment contained only a low number $(<300)$ and diversity of oligochaete species, primarily Limnodrilus cervix. No actinospores were observed in the filtered water from the worms either upon receipt of the samples or over the subsequent month. No infectious organisms were seen in squash preparations of oligochaetes.

\section{Description}

Myxidium scripta n. sp.: Type host: Trachemys scripta elegans (Wied-Neuwied, 1839) (Testudines: Emydidae).

Type locality: Turtle Farm, Assumption Parish, Louisiana, USA.

Site of infection: Coelozoic, in lumen of gall bladder, bile ductules and renal tubules.

Material deposited: Kidney from 3 turtles. H\&E and B\&B Gram stained slide of plasmodia and spores in kidney. Type specimens deposited at the Harold W. Manter Laboratory collection (HWML), University of Nebraska State Museum, Lincoln, Nebraska. Kidney from 3 female turtles (host samples \# 361-363). Type host (\# 362): Hapantotype Giemsa stained histological section of plasmodia and spores in kidney, HWML48411; Parahapantotypes Giemsa stained section and 2 B\&B Gram stained sections, HWML48412; infected kidney preserved in 95\% ethanol, HWML48414. Additional specimens found identical by SSU sequencing: infected kidney preserved in $95 \%$ ethanol from host \# 361, (HWML48413) and host \# 363 (HWML48415).

Prevalence: 4 of 6, infected when collected May 24, 2004.

Spores in cytological preparations of the kidney: (Fig. 2) In lateral view, spore body fusiform and slightly flattened on one side. Striations parallel to suture apparent on valvular surface. Two pyriform polar capsules, equal, opposed, oriented toward the ends of the spore and at a slight angle (16 to $\left.19^{\circ}\right)$ to the flattened side of the spore relative to the longitudinal axis. Mean spore measurements and range in $\mu \mathrm{m}$ (Table 1) are as follows: length 18.8 ( $\mathrm{n}=59 ; 16.6$ to 20.4 ), width 5.1 ( $\mathrm{n}=59 ; 4.6$ to 5.9), polar capsule length $6.6(\mathrm{n}=117$; 5.1 to 7.8 ), and polar capsule width 3.5 ( $\mathrm{n}=117 ; 2.6$ to 4.1). Polar filaments coiled 6 to 8 times within capsules ( $\mathrm{n}=108)$.

Spores in histological section of the kidney: Spores contain 2 conical polar capsules with the pointed end oriented to the ends of the spores. Polar capsules contain coiled polar filaments that were best observed as blue staining structures with B\&B Gram stain (Fig. 1). Mature polar capsules were red and immature polar capsules were blue with B\&B Gram stain. The mean length of 20 spores in axial cross-section was $16.67 \mu \mathrm{m}$

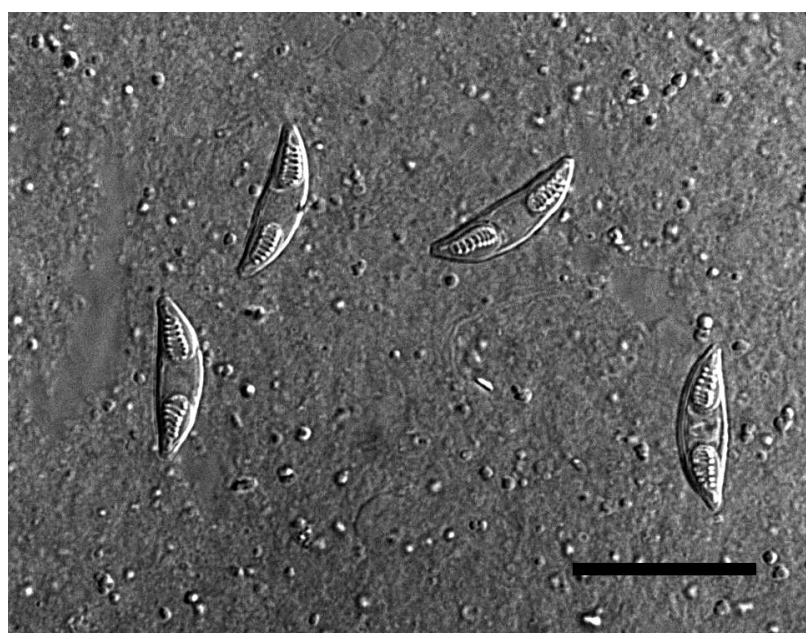

Fig. 2. Myxidium scripta n. sp. Spores from wet mount preparations of kidney. Scale bar $=20 \mu \mathrm{m}$ 
Table 1. Myxidium spp. Comparison of myxospore dimensions from reptiles. Mean measurements in $\mu$ m, range in parentheses. PCL, PCW: polar capsule length and width, respectively

\begin{tabular}{|c|c|c|c|c|c|c|c|c|}
\hline Species & Host species & Locality & Length & Width & PCL & PCW & No. of coils & Source \\
\hline M. scripta n. sp. & $\begin{array}{l}\text { Trachemys } \\
\text { scripta elegans }\end{array}$ & $\begin{array}{l}\text { Louisiana, } \\
\text { USA }\end{array}$ & $\begin{array}{c}18.8 \\
(16.6-20.4)\end{array}$ & $\begin{array}{c}5.1 \\
(4.6-5.9)\end{array}$ & $\begin{array}{c}6.6 \\
(5.1-7.8)\end{array}$ & $\begin{array}{c}3.5 \\
(2.6-4.1)\end{array}$ & $6-8$ & Present study \\
\hline M. americanum & Trionyx spinifera & USA & $(15-16)$ & $(5.5-6.0)$ & 4 & 3.5 & 3 & Eiras (2005) \\
\hline M. chelonarum & Various & USA & $\begin{array}{c}14.4 \\
(12.5-16)\end{array}$ & $\begin{array}{c}4.5 \\
(3-5)\end{array}$ & $\begin{array}{c}4.5 \\
(2.5-5)\end{array}$ & $(2-3)$ & $5-7$ & Eiras (2005) \\
\hline M. danilewskyi & Emys orbicularis & France & 12 & $3-4$ & - & - & - & $\begin{array}{l}\text { Jayasri \& Hoffman } \\
(1982)\end{array}$ \\
\hline M. hardella & Hardella thurjii & Pakistan & $\begin{array}{c}17.7 \\
(14.9-20.0)\end{array}$ & $\begin{array}{c}4.9 \\
(4.5-5.7)\end{array}$ & $\begin{array}{c}6.2 \\
(4.9-7.1)\end{array}$ & $\begin{array}{c}2.9 \\
(2.7-3.3)\end{array}$ & 7 & Garner et al. (2005) \\
\hline M. mackiei & Trionyx gangeticus & India & $16-17$ & 5 & - & - & - & Eiras (2005) \\
\hline
\end{tabular}

and maximum width was $3.0 \mu \mathrm{m}$. The central middle 'waist' between the polar capsules was slightly decreased in width with a maximum of $2.9 \mu \mathrm{m}$.

Ultrastructure using TEM: Polysporic plasmodia were located in lumina of proximal renal tubules in 1 of 2 RES whose kidneys were examined using TEM. The ectoplasm of the plasmodia was finely granular, contained vegetative nuclei and contacted microvilli of the proximal renal tubule. Plasmodia contained multiple stages of sporogony, including cell triplets and early and late disporoblasts with developing spores and mature spores. Disporoblasts containing developing and mature capsulogenic spores were observed in axial and transverse section. Early developing spores contained polar bodies with central electron dense bodies and no differentiated polar filament structures. Mature spores contained polar capsules with polar filaments, or ridged valves enclosing an electron lucent artifact surrounded by membrane bound electron lucent matrix (Fig. 3a). Mature spores in transverse cross-section had a 'cog-wheel' structure formed by 2 asymmetrical valves - one with 13 ridges and the other with 10 ridges - that overlapped to form sutural ridges (Fig. 3b). Late disporoblasts were composed of an amoeboid sporoplasm cell enclosing 2 mature capsulogenic cells with developed polar capsules (Fig. 3c). An axial section through a polar capsule revealed filaments with 6 to 8 coils and a double-layered polar capsule membrane (Fig. 3d).

Etymology: The specific epithet is named for the species of host turtle.

\section{Remarks}

Wet mount preparations of kidney tissue from Trachemys scripta elegans revealed elongate fusiform spores with 2 polar capsules morphologically consistent with the genus Myxidium (Figs. 2 \& 4). As DNA sequencing and TEM were not used in previous stud- ies of Myxidium species from North American turtles, data from spore and polar capsule dimensions must be relied upon to make comparisons between descriptions. M. americanum (Kudo 1919) is the closest taxon of the 2 previously described species as a disporoblastic organism, with 8 to 10 striae identified from renal tubules (Mitchell 1967). The term 'striae' corresponds to the valvular ridges observed as 'cogteeth' by TEM cross-section in the current study. $M$. scripta $\mathrm{n}$. sp. had 10 to 13 ridges per valve and this was observed by light microscopy of cytological preparations as 8 to 10 striae. However, for M. americanum Kudo, Johnson (1969) described 3 coils per polar filament, in contrast to the 6 to 8 coils observed for $M$. scripta n. sp. Additionally, in fresh preparations $M$. americanum spores were slightly shorter than $M$. scripta n. sp. (Table 1). M. chelonarum has been described from RES turtles, but spores of this species were considerably shorter $(14 \mu \mathrm{m})$, had fewer striae (4 to 6), and often had 3 or as many as 5 polar capsules. In addition, Johnson (1969) describes striae of $M$. chelonarum as obliquely angled to the longitudinal axis of the spore, whereas those of M. scripta n. sp. run parallel to the axis. The number of polar filament coils for $M$. chelonarum (5 to 7) was closer to $M$. scripta n. sp. (7 to 8) (Mitchell 1967). Dimensions of M. scripta n. sp. spores overlap somewhat with those of M. mackiei. However, by TEM, M. scripta n. sp. had fewer (10) and wider valvular ridges than $M$. mackiei (12 to 13$)$, with a ridge-to-valley width ratio closer to $2: 1$ in the former and approximately 1:1 in the latter. As in other studies (Helke \& Poynton 2005), longitudinal striae were not observed by histology. It should be noted that a decrease in myxozoan spore dimensions obtained from fixed material in histologic sections is expected as the result of shrinkage by alcohol during preparation (Parker \& Warner 1970). Here, the mean length was $16.8 \mu \mathrm{m}$ from histology and $18.8 \mu \mathrm{m}$ from fresh cytological preparation, indicating an $11 \%$ reduction. As spores in all infected 

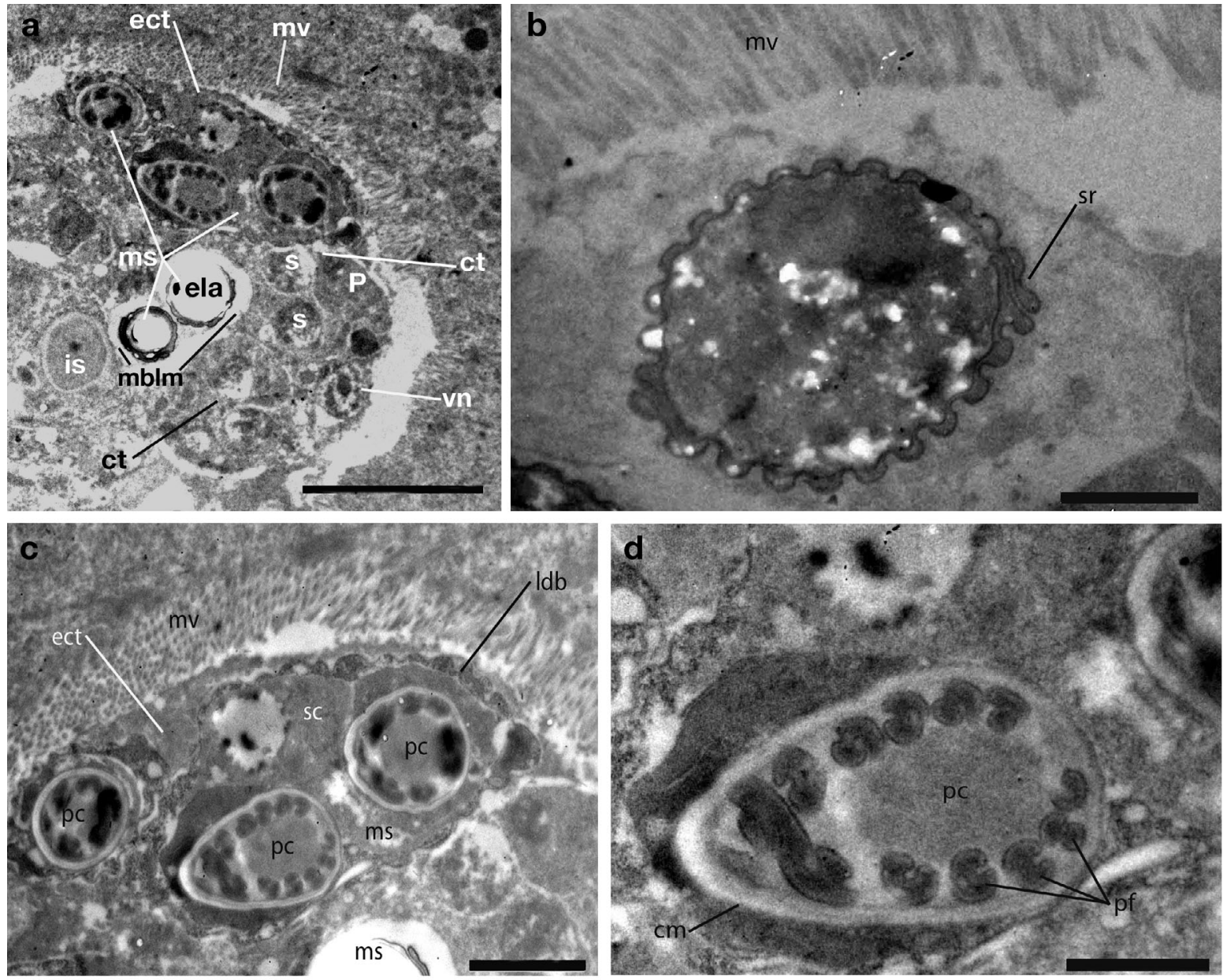

Fig. 3. Myxidium scripta n. sp invading Trachemys scripta elegans. (a) T. s. elegans renal tubule, kidney. Partial polysporic plasmodia with multiple stages of sporogony including cell triplets (ct) with one primary (P) and 2 secondary cells (s), early disporoblast and late disporoblast containing immature spores (is) and mature spores (ms). Immature spores contained polar bodies with a central electron dense body and no polar filaments. Mature spores contained polar capsules with polar filaments, or ridged valves enclosing an electron lucent artifact (ela) surrounded by membrane bound electron lucent matrix (mblm). The ectoplasm (ect) of the plasmodia contacts the microvilli $(\mathrm{mv})$ of the proximal renal tubule and contains vegetative nuclei (vn). Scale bar $=$ $5 \mu \mathrm{m}$. (b) A single mature spore in transverse cross-section near renal tubular microvilli (mv) demonstrating 'cog-wheel' structure formed by 2 asymmetrical valves - one with 13 ridges and the other with 10 ridges - meeting to form 2 overlapping sutural ridges (sr). Scale bar $=1 \mu \mathrm{m}$. (c) Ectoplasm (ect) in contact with renal tubular microvilli (mv) surrounds a late disporoblast (ldb) composed of an amoeboid sporoplasmic cell (sc) enclosing 2 mature spores with developed polar capsules (pc). Figure also contains a partial mature spore (ms) with electron lucent artifact and polar capsules within adjacent late disporoblast. Scale bar $=$ $2 \mu \mathrm{m}$. (d) An axial section through a polar capsule (pc) containing polar filaments (pf) coiled 6-7 times and a double-layered polar capsule membrane $(\mathrm{cm})$. Scale bar $=1 \mu \mathrm{m}$

turtles were morphologically similar and partial DNA sequences were identical, it is assumed that the infections in these RES represent a single species of Myxidium.

\section{Phylogenetic analysis}

Phylogenetic analysis of SSU rDNA places Myxidium scripta n. sp. as a sister taxon to a clade comprised of other Myxidium spp., as well as Zschokkella,
Sphaeromyxa, Chloromyxum, and Sphaerospora species (Fig. 5). The 4 methods of phylogenetic analysis yielded trees that were largely congruent. A notable difference was the placement of M. scripta n. sp. as sister to Raabeia KAB-2001 by distance analysis. Elsewhere, the placement of Synactinomyxon 'type 1' was somewhat unstable, but this did not involve the clade containing M. scripta n. sp. The other Myxidium species from reptiles ( $M$. chelonarum and $M$. hardella) formed a well-supported clade to the exclusion of $M$. scripta n. sp. (Fig. 5). 

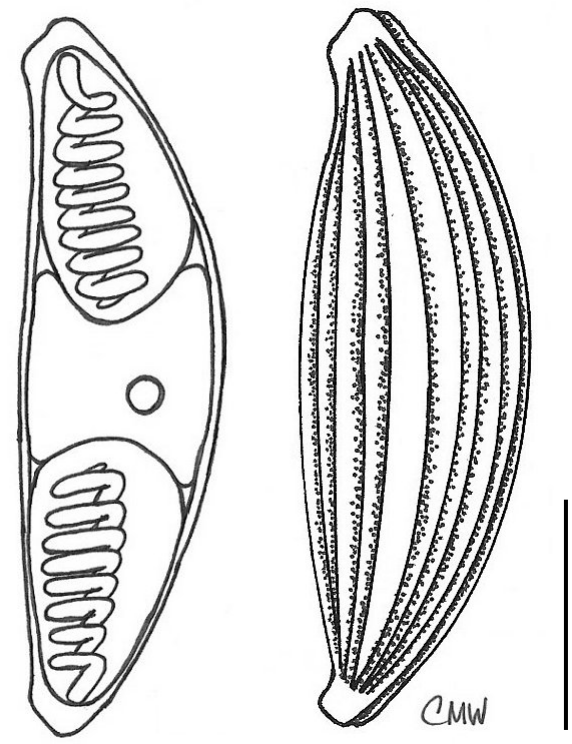

Fig. 4. Myxidium scripta n. sp. internal and external features. Scale bar $=5 \mu \mathrm{m}$

\section{DISCUSSION}

The unrelated disease that resulted in euthanasia of 6 ill turtles from a commercial turtle farm provided an opportunity to explore the prevalence and significance of Myxidium scripta n. sp. in RES. M. scripta n. sp. infection was not detected in 2 turtles, was considered incidental in 3 turtles and was associated with severe nephritis in 1 turtle. This myxozoan was seen in renal tubules of 3 turtles, the gall bladder of 2 turtles and bile ductules of 1 turtle. Similarly $M$. americanum, $M$. hardella, and M. mackiei also infect both urinary and biliary tracts, while $M$. chelonarum has been primarily identified from the gall bladder (Johnson 1969, Garner et al. 2005, Helke \& Poynton 2005).

The life cycle of this parasite has not been determined. Mud samples from the pond where these turtles originated were examined for the presence of annelids releasing actinospores that might correspond to the alternate spore stage of Myxidium scripta n. sp. No actinospores were identified, although the low diversity of annelid species in the sample suggests that it may not have been representative of the population in the ponds.

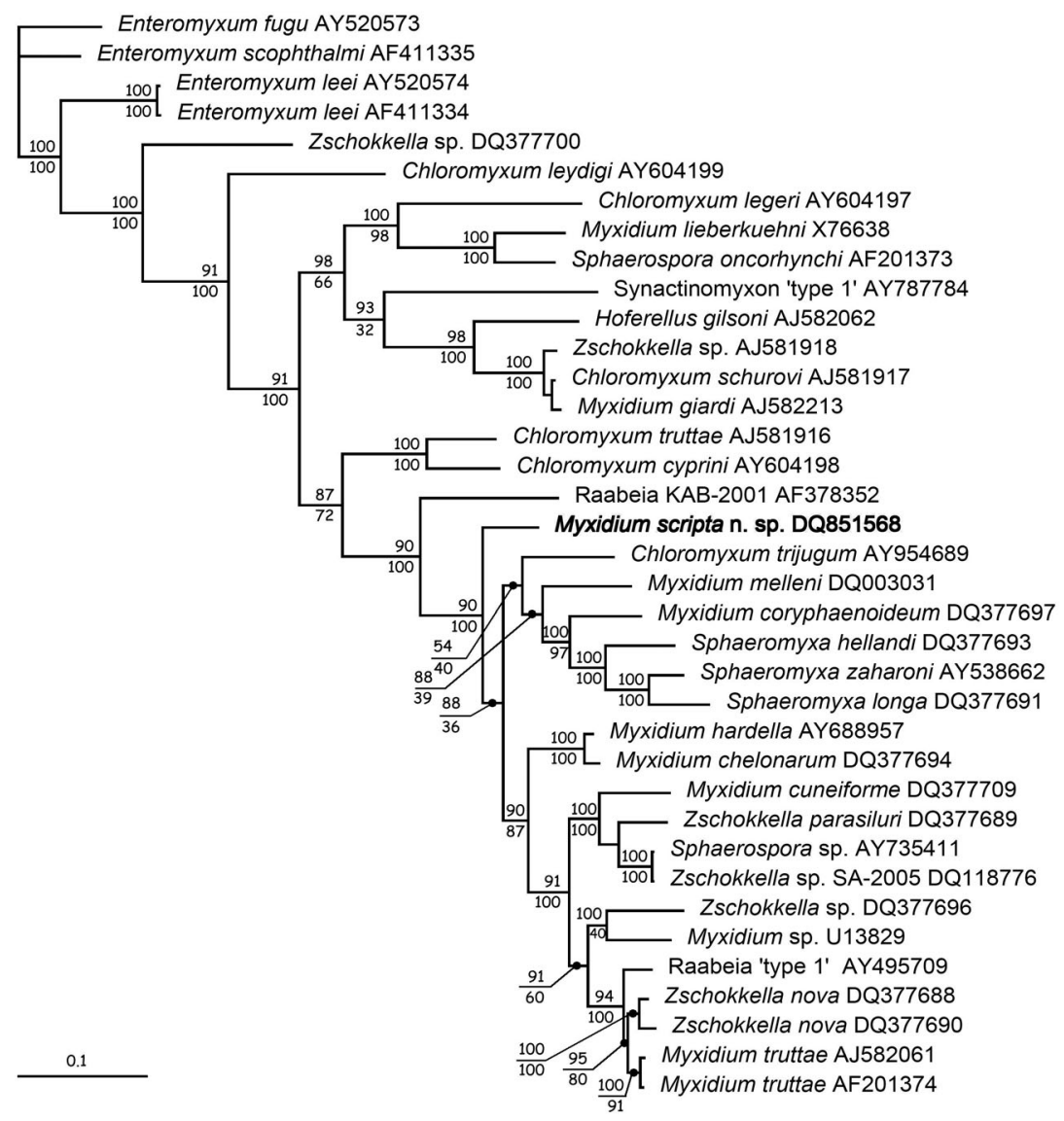

Fig. 5. Majority rule consensus tree from Bayesian analysis of small subunit ribosomal DNA of Myxidium scripta n. sp. and closely related myxozoan species. GenBank accession numbers are listed beside species name. Clade credibility values are shown above nodes and bootstrap support values from parsimony analysis are shown below nodes 
Although the life cycle is not known, it is likely that the high population density of these farmed turtles (25 000 per $0.4 \mathrm{hm}^{2}$ ) probably amplified parasite transmission. In addition, other species of turtles or vertebrates could act as reservoir hosts for the parasite. For example, Johnson's extensive survey of 21 free ranging turtle species reported that Myxidium chelonarum was present in as many as 14 species throughout the Southern United States and Mexico (Johnson 1969, Holland \& Jackson 1974). Regarding pathogenesis in the host, like $M$. hardella, sporogonic plasmodia were observed in the lumina of bile duct and renal tubules (Garner et al. 2005). This coelozoic distribution suggests the parasite initially ascends into the upper biliary and urinary systems from the small intestine and urinary cloaca, respectively.

The turtle with the greatest number of overall spores in renal tubules also had severe nephritis, with greater than 20 spores identified in cross-sections of affected tubules. B\&B Gram, Warthin-Starry, GMS, Giemsa, Fite's acid fast and Zeihl-Neelsen acid fast stains failed to demonstrate dual infection by another parasite or bacteria. Proximal convoluted tubules were identified by intracytoplasmic globular structures (lysosomes) that were accentuated with B\&B Gram stain and Fite's acid fast stain. Of these stains, B\&B Gram stain had greatest staining affinity for polar capsules in early stages of development. Giemsa stain identified the polar filaments of late stages but failed to stain the capsules of early stage spores. Plasmodia-like structures and granulomatous nephritis were similar to those depicted for Myxidium rhodei infection in renal tubules of flat bream Abramis brama (Longshaw et al. 2005). Dilated tubules also contained structures similar to plasmodium-associated golden globules, as seen in renal tubules of turtles infected with $M$. mackiei (Helke \& Poynton 2005). Blockage of tubules leading to increased pressure, gradient alterations and possible immune mediated disease have been proposed as mechanisms of tubular damage (Garner et al. 2005). The presence of large plasmodia with numerous spores found in Chloromyxum sp. infection of Asian horned frogs Megophrys nasuta has been shown to cause blockage of renal tubules and distension of glomerular spaces leading to leakage of urine and interstitial nephritis (Duncan et al. 2004). Although Tetracapsula bryosalmonae (formerly $T$. renicola), the myxozoan responsible for proliferative kidney disease of salmonid fish, produced interstitial nephritis in response to extrasporogonic stages (Kent et al. 2000), these stages of M. scripta n. sp. were not identified in RES in the current study.

Structures consistent with Type I plasmodia were observed in some renal tubules and these structures were morphologically similar to Type I plasmodia depicted for Myxidium pfeifferi in the renal tubules of roach Rutilus rutilus (Longshaw et al. 2005). Despite histologic similarities with other species, we were unable to distinguish vegetative nuclei present in primary cells and secondary cells of early disporoblasts from host mononuclear inflammatory cells and degenerated heterophils using light microscopy. Although TEM was able to confirm developing stages of sporogony, it was not possible to correlate stages seen using TEM with those seen using light microscopy. Renal tubule epithelial damage consisting of shearing, compression and loss of microvilli on the luminal surface of epithelial cells was documented in M. mackiei (Helke \& Poynton 2005) but was not observed in the TEM images of the current study. Microvilli were observed in TEM images from this case but specific microvillus-plasmodium interaction could not be documented. In order to visualize plasmodia under the light microscope, the gall bladder and urinary bladder should ideally be opened into Petri dishes containing $0.7 \%$ $\mathrm{NaHCO}_{3}$ solution and examined with a stereomicroscope at time of necropsy (Johnson 1969, Jirků et al. 2006). Large plasmodia, such as those of $M$. chelonarum (16 to $180 \mu \mathrm{m}$ in diameter) are contained in a fragile ectoplasm and are free in the bile within the gall bladder. These structures are likely to break up and escape with fluid loss during histology processing and thus elude detection.

Although Myxidium chelonarum has been reported to parasitize RES (Johnson 1969), M. scripta n. sp. was clearly distinct based on several morphological characteristics. Whereas both species share certain features, such as spores that are fusiform and flattened on one side in lateral view, and polar capsules oriented towards ends of spore but at a slight angle to the longitudinal axis, differentiation of these species can be accomplished by measurement of spore length $(M$. chelonarum is 12.5 to $16 \mu \mathrm{m}$ and $M$. scripta n. sp. is 16.6 to $20.4 \mu \mathrm{m}$ ) and by the presence of obliquely angled valvular striae in $M$. chelonarum versus longitudinal striae in M. scripta n. sp. Morphological or pathological variation among myxozoa have often been interpreted as intraspecific variation (Jirků et al. 2006, Whipps \& Diggles 2006) and molecular analyses have both supported (Blaylock et al. 2004) and rejected (Adlard et al. 2005, Easy et al. 2005) this assertion. Thus, morphological differences may be either interor intraspecific, and molecular analyses have illuminated the more likely alternative. Because sequence data is lacking for $M$. chelonarum, it is unclear if this represents a species complex. Still, our finding of a distinct species, in a known host for $M$. chelonarum, indicates that RES is susceptible to infection with more than one myxozoan species. Molecular data support a lack of host specificity for other myxozoans; Kudoa 
thyrsites for example, is known to infect over 37 fish species (Whipps \& Kent 2006). The only SSU sequence available for $M$. chelonarum (GenBank record DQ377694) originated from a previously unlisted host and location, the brown roofed turtle Kachuga smithi from South Asia (Fiala 2006). Although morphologically similar, comparison of DNA sequences of $M$. chelonarum from listed hosts in North America is worth further investigation. $M$. immersum and $M$. serotinum from amphibians also appear to lack host specificity (Eiras 2005) and may represent multiple species. DNA sequencing will be needed to determine the phylogenetic relationship of these myxozoan parasites.

Recent studies have shown congruency in spore valve morphology from Asian and American species of Myxidium (Helke \& Poynton 2005). Phylogenetically, M. hardella and M. chelonarum, both from Asian turtles, formed a well-supported grouping. We hypothesized that all Myxidium species from turtles may be a distinct myxozoan lineage based on the clustering of these Asian species, which were also the primary BLAST hits for M. scripta n. sp. However, we consistently found $M$. scripta n. sp. to be an outgroup to these and several other Myxidium species (Fig. 5). Therefore, these data suggest that the colonization of reptile hosts has occurred more than once in myxozoan evolution. Whether all Myxidium species from North American and Asian reptiles form 2 distinct lineages is worth further investigation.

This raises interesting questions regarding the wide distribution of a similar metazoan species infecting freshwater turtles on opposite sides of the Northern Hemisphere. The specific identification of chelonian Myxidium may hold clues to the evolutionary dissemination of various turtle species. Determination of the Myxidium life cycle in turtles should be a focus of future research.

Acknowledgements. We thank Dr. E. Greiner (for editing) and G. Foster (for identification of acanthocephalan and nematodes); G. Eldred, N. A. Sliess and W. Connor (for histology), Dept. of Infectious Disease and Pathology, College of Veterinary Medicine, University of Florida; Dr. M. A. Mitchell, Dept. of Veterinary Clinical Sciences, School of Veterinary Medicine, Louisiana State University; and S. Atkinson, Dept. of Microbiology, Oregon State University (examination of pond sediment and oligochaete identification).

\section{LITERATURE CITED}

Adlard RD, Bryant MS, Whipps CM, Kent ML (2005) Multivalvulid myxozoans from eastern Australia: three new species of Kudoa from scombrid and labrid fishes of the Great Barrier Reef, Queensland, Australia. J Parasitol 91:1138-1142

Blaylock RB, Bullard SA, Whipps CM (2004) Kudoa hypoepicardialis $\mathrm{n}$. sp. (Myxozoa: Kudoidae) and associated lesions from the heart of seven perciform fishes in the northern Gulf of Mexico. J Parasitol 90:584-593

Bosanquet WC (1910) Brief notes on two Myxosporidan organisms (Pleistophora hippoglossoides, n. sp. and Myxidium mackiei n. sp.). Zool Anz 35:434-438

Duncan AE, Garner MM, Bartholomew JL, Reichard TA, Nordhausen RW (2004) Renal myxosporidiasis in Asian horned frogs (Megophrys nasuta). J Zoo Wildl Med 35:381-386

Easy RH, Johnson SC, Cone DK (2005) Morphological and molecular comparison of Myxobolus procerus (Kudo, 1934) and $M$. intramusculi n. sp. (Myxozoa) parasitising muscles of the trout-perch Percopsis omiscomaycus. Syst Parasitol 61:115-122

Eiras JC (2005) An overview on the myxosporean parasites in amphibians and reptiles. Acta Parasitol 50:267-275

Ernst CH, Barbour RW, Lovich JE (1994) Turtles of the United States and Canada. Smithsonian Institution Press, Washington, DC, p 113 \& 300

Fiala I (2006) The phyologeny of Myxosporea (Myxozoa) based on small subunit ribosomal RNA gene analysis. Int J Parasitol 36:1521-1534

Garner MM, Bartholomew JL, Whipps CM, Nordhausen RW, Raiti PR (2005) Renal myxozoanosis in crowned river turtles Hardella thurjii: description of the putative agent, Myxidium hardella n. sp. by histopathology, electron microscopy, and DNA sequencing. Vet Pathol 42:589-595

> Helke KL, Poynton SL (2005) Myxidium mackiei (Myxosporea) in Indo-Gangetic flap-shelled turtles Lissemys punctata andersonii: parasite-host interaction and ultrastructure. Dis Aquat Org 63:215-230

Holland LH, Jackson CG Jr (1974) Occurrence of Myxidium chelonarum in Florida turtles (Cnidosporida: Myxosporida). ASB Bull 21:62

Holz RM, Holz P (1995) Electrocardiography in anaesthetized red-eared sliders (Trachemys scripta elegans). Res Vet Sci 58:67-69

Jayasri M, Hoffman GL (1982) Review of Myxidium (Protozoa:Myxozoa:Myxosporea). Protozool Abstr 6:61-91

Jirků M, Bolek MG, Whipps CM, Janovy J Jr, Kent ML, Modrý D (2006) A new species of Myxidium (Myxosporea: Myxidiidae), from the western chorus frog, Pseudacris triseriata triseriata, and Blanchard's cricket frog, Acris crepitans blanchardi (Hylidae) from eastern Nebraska USA: morphology, phylogeny and critical comments on amphibian Myxidium taxonomy. J Parasitol 92:611-619

Johnson CA (1969) A redescription of Myxidium chelonarum Johnson 1969, (Cnidospora: Myxidiidae) from various North American turtles. J Protozool 16:700-702

Kent ML, Khattra J, Hedrick RP, Devlin RH (2000) Tetracapsula renicola (Myxozoa: Saccosporidae); the PKX myxozoan - the cause of proliferative kidney disease of salmonid fishes. J Parasitol 86:103-111

Kent ML, Andree KB, Bartholomew JL, El-Matbouli M and others (2001) Recent advances in our knowledge of the Myxozoa. J Eukaryot Microbiol 48:395-413

Kudo RR (1919) Studies of Myxosporidia. A synopsis of genera and species. Ill Biol Monogr 5. Illinois University Press, Chicago, IL

> Lom J, Arthur JR (1989) A guideline for the preparation of species descriptions in Myxosporea. J Fish Dis 12:151-156

> Lom J, Dyková I (2006) Myxozoan genera: definition and notes on taxonomy, life-cycle terminology and pathogenic species. Folia Parasitol (Praha) 53:1-36

> Longshaw M, Frear PA, Feist SW (2005) Description and pathogenicity of myxozoan (Myxozoa: Myxosporea) parasites of juvenile cyprinids (Pisces: Cyprinidae). J Fish Dis 28:489-508 
Luna LG (1968) Manual of histologic staining methods of the Armed Forces Institute of Pathology, 3rd edn. McGrawHill Book Company, New York, p 36-38 \& 222-223

McAllister CT, Trauth SE (1995) New host records for Myxidium serotinum (Protozoa: Myxosporea) from North American amphibians. J Parasitol 81:485-488

Mitchell LG (1967) Myxidium macrocheili n. sp. (Cnidospora: Myxidiidae) from the largescale sucker Catostomus macrocheilus Girard, and a synopsis of the Myxidium of North American freshwater vertebrates. J Protozool 14: 415-424

Padros F, Palenzuela O, Hispano C, Tosas O, Zarza C, Crespo S, Alvarez-Pellitero P (2001) Myxidium leei (Myxozoa) infections in aquarium-reared Mediterranean fish species. Dis Aquat Org 47:57-62

Parker JD, Warner MC (1970) Effects of fixation, dehydration and staining on dimensions of myxosporidian and microsporidian spores. J Wildl Dis 6:448-456

Posada D, Crandall KA (1998) MODELTEST: testing the model of DNA substitution. Bioinformatics 14:817-818

Reynolds ES (1963) The use of lead citrate at high pH as an

Editorial responsibility: Alex Hyatt,

Geelong, Victoria, Australia electron-opaque stain in electron microscopy. J Cell Biol $17: 208-212$

Ronquist F, Huelsenbeck JP (2003) MrBayes 3: Bayesian phylogenetic inference under mixed models. Bioinformatics 19:1572-1574

Spurr AR (1969) A low-viscosity epoxy resin embedding medium for electron microscopy. J Ultrastruct Res 26: $31-43$

Swofford DL (1998) PAUP*. Phylogenetic Analysis Using Parsimony ( ${ }^{*}$ and Other Methods). Version 4. Sinauer Associates, Sunderland, MA

Thompson JD, Gibson TJ, Plewniak F, Jeanmougin F, Higgins DG (1997) The Clustal X windows interface: flexible strategies for multiple sequence alignment aided by quality analysis tools. Nucleic Acids Res 25:4876-4882

Whipps CM, Diggles BD (2006) Kudoa alliaria in flesh of Argentinian hoki Macruronus magellanicus (Gadiformes; Merlucciidae). Dis Aquat Org 69:259-263

Whipps CM, Kent ML (2006) Phylogeography of the cosmopolitan marine parasite Kudoa thyrsites (Myxozoa: Myxosporea). J Eukaryot Microbiol 53:364-373

Submitted: August 6, 2007; Accepted: February 11, 2008 Proofs received from author(s): July 12, 2008 